\title{
Processo de manufatura de um sistema por piso móvel para transporte de biomassa
}

\author{
Eduardo Amorim Benincá* Altieres Benincá * \\ Oureste Elias Batista ${ }^{* *}$ \\ *BN-ELETRO, ES, (e-mail: eduardoamorimb@hotmail.com, \\ altieresbeninca@hotmail.com) \\ ** Departamento de Engenharia Elétrica, Universidade Federal do \\ Espirito Santo, ES, (e-mail: oureste.batista@ufes.br)
}

\begin{abstract}
The use of biomass for boiler feeding in the industrial chain is widely disseminated in Brazil. Located in this area, the work describes the manufacturing process of a moving floor system for transporting biomass and a complementary system for the loading of coffee straw, aiming at reducing the cost of the implement. For this, steel profiles were used, unlike most commercial models based on aluminum. The system presented $1500 \mathrm{~kg}$ lighter than one for the same category of trucks, expansion of load capacity at $7 \mathrm{~m}^{3}$, allied to a reduction of, approximately, $40 \%$ of the cost. The system is used, in daily operation, for 5 years without presenting structural problems.

Resumo: A utilização de biomassa para alimentação de caldeiras na cadeia industrial é amplamente difundida no Brasil. Situado nesta área, o trabalho descreve o processo de manufatura de um sistema de piso móvel para transporte de biomassa e de um sistema complementar para o carregamento de palha de café, visando a redução no custo do implemento. Para isso, utilizouse perfis em aço, diferentemente da maioria dos modelos comerciais baseados em alumínio. O sistema apresentou-se $1500 \mathrm{~kg}$ mais leve do que um para de mesma categoria de caminhões, ampliação da capacidade de carga $\mathrm{em} 7 \mathrm{~m}^{3}$, aliados a uma redução de, aproximadamente, $40 \%$ do custo. O sistema é utilizado, em operação diária, há 5 anos sem apresentar problemas estruturais.
\end{abstract}

Keywords: Moving floor; mechanical conveyors; reciprocating floor conveyor; self-unloading; walking floor.

Palavras-chaves: Piso móvel; carregadores mecânicos; piso carregador alternante; descarregamento automático; piso ambulante.

\section{INTRODUÇÃO}

Sistemas de deslocamento de carga por piso móvel têm ganhando espaço no transporte rodoviário por proporcionarem aplicabilidade em diversos tipos de cargas, desde paletizadas e até à granel. No Brasil, destaca-se principalmente no transporte de biomassa (cavaco de madeira e bagaço de cana) para abastecimento de caldeiras do setor industrial. Ao permitir a mudança do tipo de carga a cada percurso, cria-se a possibilidade de um melhor gerenciamento dos fretes, aumentando, assim, a lucratividade por quilômetro percorrido pelo caminhão (Miao et al., 2012; Drozdziel et al., 2017; Mustafa et al., 2016).

O sistema de descarregamento por piso móvel apresenta vantagens sensíveis em comparação aos sistemas convencionais: baus, carretas com descarregamento lateral e sistemas basculantes. Em relação aos dois primeiros, a principal vantagem é dispensar a necessidade de mão de obra para o deslocamento do material do centro da caixa de carga até a sua extremidade. Há, portanto, redução do custo, uma vez que só necessita de uma pessoa para operar o sistema,

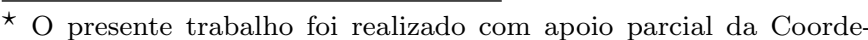
nação de Aperfeiçoamento de Pessoal de Nível Superior - Brasil (CAPES) - Código de Financiamento 001.
}

e do tempo de carga e descarga, dado que o trabalho é automatizado (Lewandowski, 2014; Bolsen, 2018).

Em relação ao sistema basculante, o de piso móvel não apresenta deslocamento do centro de gravidade no processo de descarregamento, o que o torna um sistema muito mais seguro, não estando suscetível ao risco de tombamento gerado por desnivelamento do solo, que é um problema muito frequente nesta forma de descarregamento (Kwo, 1958; Muth and White, 1979). Outra vantagem é a operação em ambientes fechados, uma vez que não necessita de galpões com altura elevada. Apenas a altura miníma para a circulação do implemento, diferentemente dos caminhões basculantes que elevam a caixa de carga no descarregamento. Além disso, obtém-se uma capacidade de carga máxima muito superior, podendo chegar a $100 \mathrm{~m}^{3}$, enquanto o basculante não ultrapassa $65 \mathrm{~m}^{3}$ (McGuire, 2009; Williams and Çelik, 1998).

No Brasil uma das grandes fornecedoras de pisos móveis é a multinacional Holandesa Hyva, que comercializa o produto desde 2002 em território nacional, e a RodoVale Implementos Rodoviários. Ambas produzem o piso em alumínio, com um custo ainda elevado. O presente trabalho descreve, então, o processo de construção de um sistema de carga e descarga automatizada por piso móvel todo em 
aço, com o compromisso de reduzir o custo da solução, sem comprometer o seu peso final.

\section{PRINCIPIO DE FUNCIONAMENTO}

O sistema de piso móvel é composto por um conjunto de perfis móveis distribuídos longitudinalmente e instalados em reboques, carrocerias e carretas. O conjunto substitui o piso convencional e é acoplado mecanicamente a atuadores hidráulicos (Foster, 1985). Este sistema de potência é composto por três pistões ligados aos perfis de forma a promover a movimentação alternada em conjuntos correspondentes a 1/3 da área total do fundo (Skocir, 2018). A movimentação da carga ocorre em decorrência da variação do atrito com o piso, que, por sua vez, possui uma dinâmica caracterizada por quatro etapas consecutivas (Foster, 1989).

Etapa 1 - Os três pistões hidráulicos movem todos os perfis em uma mesma direção, como a força peso e a força de atrito é maior no piso do que nas paredes a carga se movimenta na direção do movimento do piso, como ilustrado pela Figura 1.

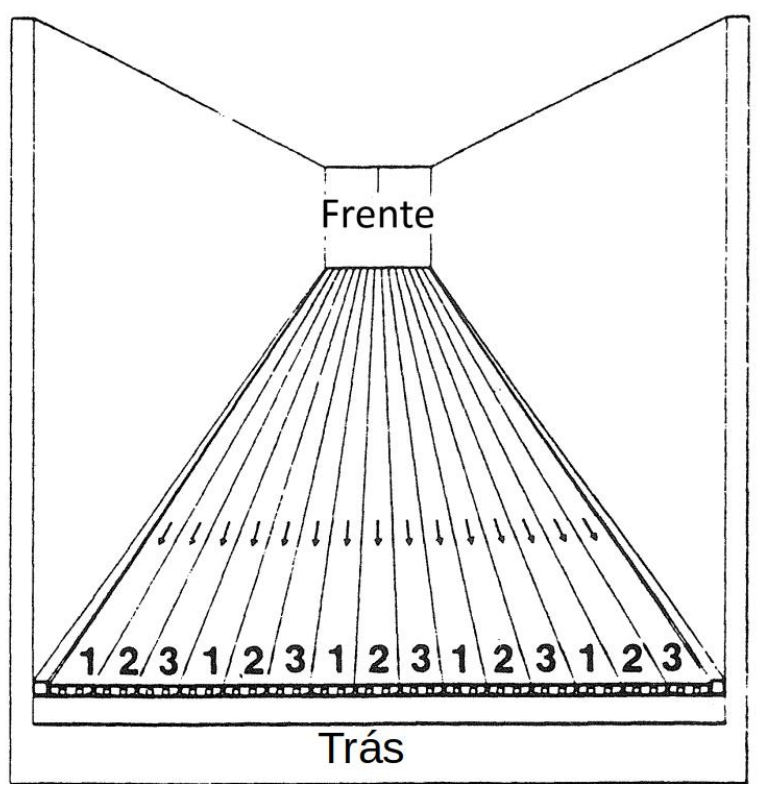

Figura 1. Etapa 1, adaptada de Fayed and Skocir (1996)

Etapa 2 - um conjunto de perfis intercalados e distribuídos correspondentes a $1 / 3$ da área total é movimentado, ficando assim $2 / 3$ da área total parada, como ilustrado pela Figura 2.

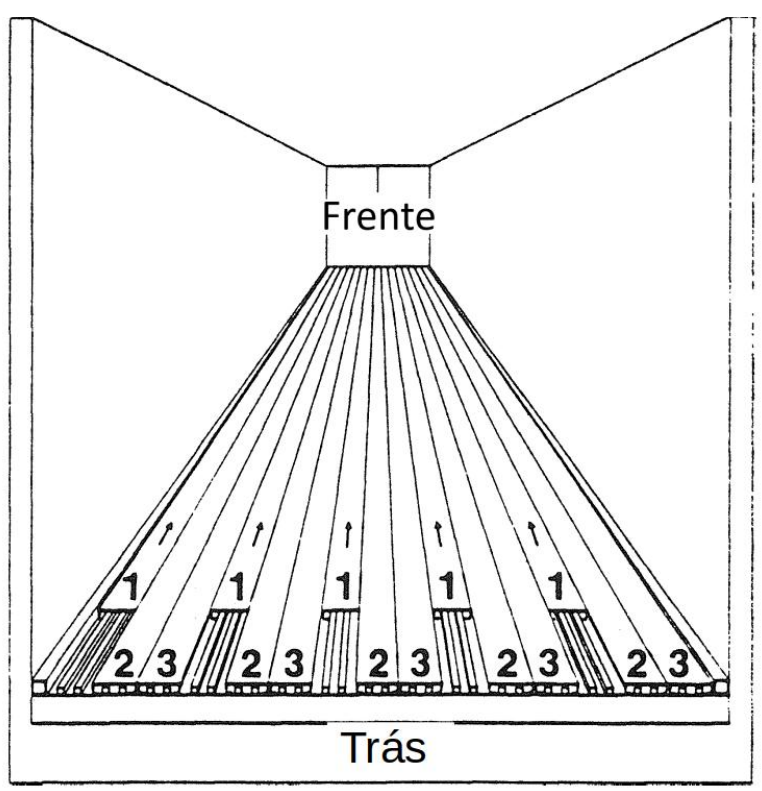

Figura 2. Etapa 2, adaptada de Fayed and Skocir (1996)

Etapa 3 - Outro conjunto de perfis, correspondentes a $1 / 3$ da área, é movimentado, ficando $2 / 3$ da área parada, como ilustrado pela Figura 3.

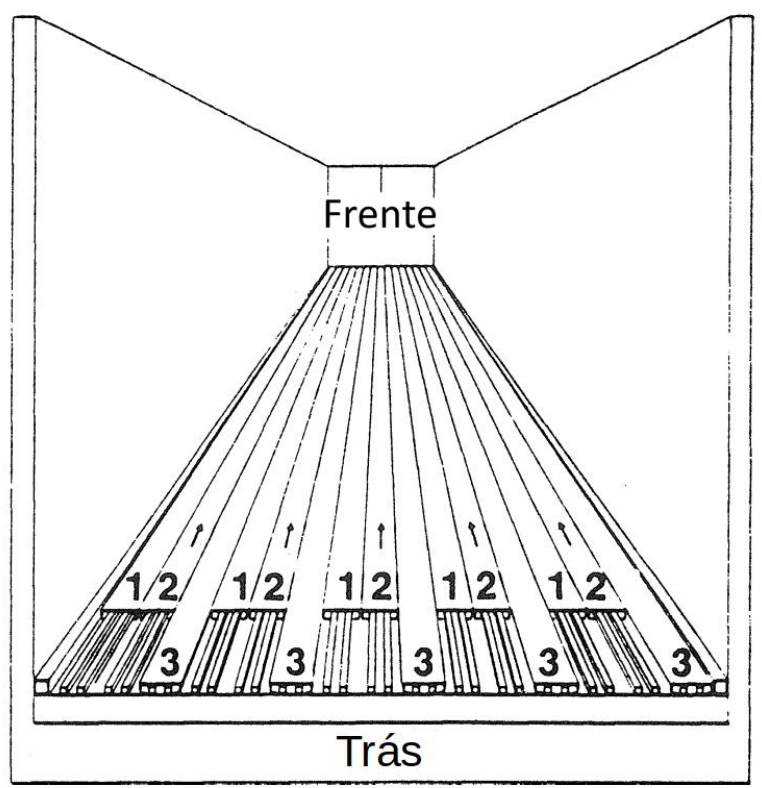

Figura 3. Etapa 3, adaptada de Fayed and Skocir (1996)

Etapa 4 - Outro conjunto de perfis, correspondentes a $1 / 3$ da área, é movimentado, ficando $2 / 3$ da área parada. Neste ponto, os três conjuntos estarão alinhados, como ilustrado na Figura 4, e o sistema será conduzido a repetir as etapas. 


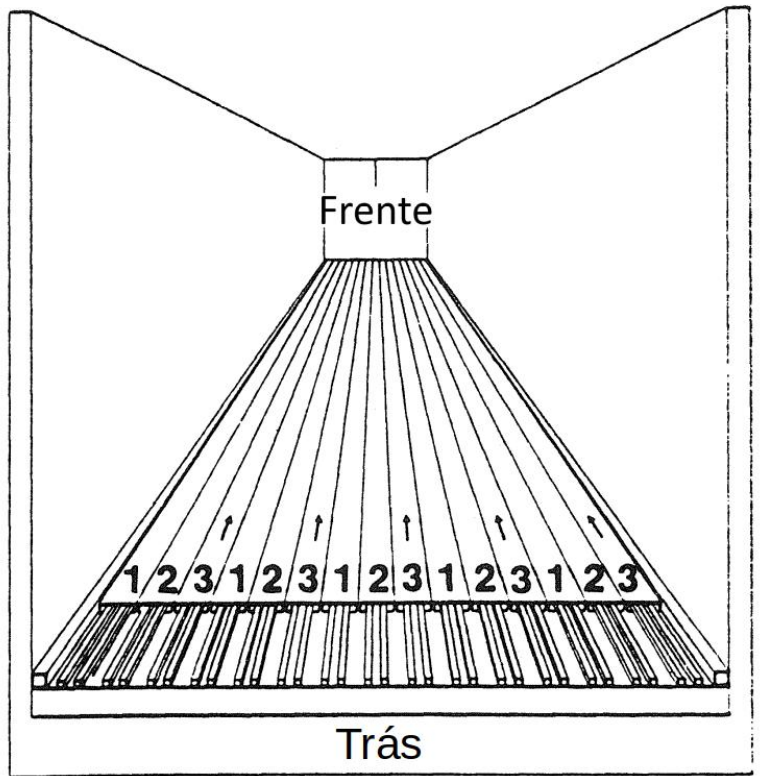

Figura 4. Etapa 4, adaptada de Fayed and Skocir (1996)

Como a força de atrito nas etapas 2,3 e 4 é menor do que na etapa 1 , devido ao fato de movimentar apenas $1 / 3$ da área total e $2 / 3$ permanecerem paradas, a resultante da força de atrito é sempre maior no conjunto com maior área. Com isso, a força de atrito entre o piso e a carga, na movimentação de $1 / 3$ da área total, não é suficiente para mover a carga. O ciclo dessas quatro etapas se repete até que a carga seja toda retirada ou carregada. A diferença entre a retirada e o carregamento se dá pela reversão do ciclo (Skocir, 2018).

A velocidade de deslocamento esta diretamente relacionada com a frequência de movimentação dos perfis, que é definida pela vasão da bomba hidráulica, necessária para fornecer o fluxo de óleo para os pistões. A massa máxima da carga a ser movimentada depende exclusivamente do torque transferido para o sistema. Este depende da pressão máxima exercida pela bomba em relação à área dos êmbolos nos pistões. A pressão hidráulica, responsável pelo sistema de potência, é gerada por uma bomba hidráulica acoplada à uma tomada de força, ligada à caixa de marcha do caminhão. O controle do movimento é feito por um comando hidráulico acionado por contatos de fim de curso acoplados aos pistões(Williams and Çelik, 1998).

\section{CONSTRUÇÃO DO PISO MÓVEL}

Visando a redução de custo, optou-se por construir todo o sistema utilizando perfis e chapas de aço convencionais, dispensando a produção de peças sob medida. Como ilustrado na Figura 5, para a sustentação do piso e da caixa de carga, foi montado um chassi composto por duas vigas em I, de 6 polegadas, que apoiadas longitudinalmente sobre o chassi do caminhão. Perpendicularmente a elas, foram fixados perfis em I, de 3 polegadas, para dar suporte ao piso e as laterais da caixa de carga (Wang et al., 2014).

Diferentemente da maioria dos pisos comerciais, substituiuse os perfis de alumínio do fundo, por perfis enrijecidos de $100 \mathrm{~mm}$ de largura por $2 \mathrm{~mm}$ de espessura. Esses perfis deslizam sobre chapas de tecnil, presas a um suporte metálico

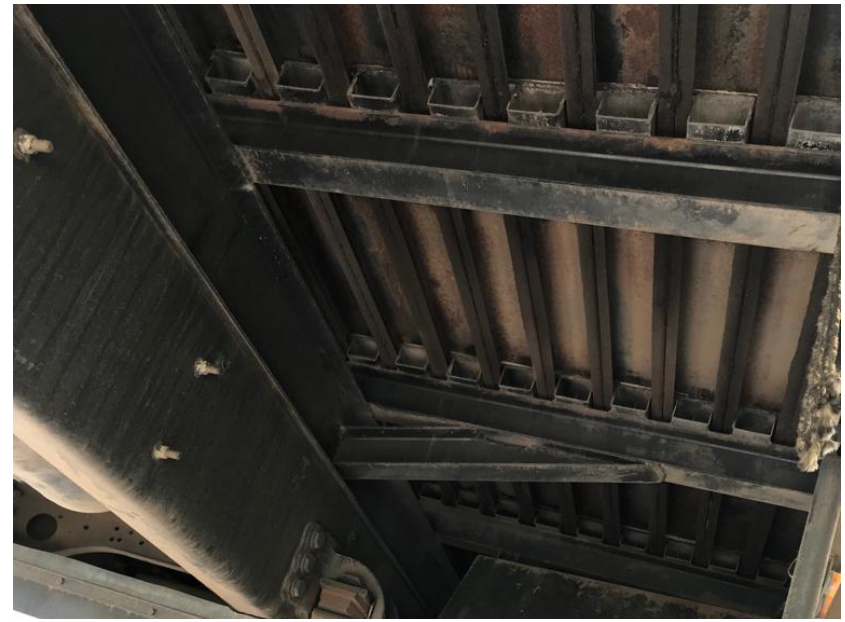

Figura 5. Estrutura de sustentação.

cuja finalidade é reduzir o atrito e evitar esforços excessivos, conforme ilustrado na Figura 6. Na parte inferior ao suporte, como é possível notar na Figura 7, foi fixada uma chapa metálica para evitar a elevação dos perfis do fundo quando a caixa de carga estiver vazia, durante o deslocamento do implemento em terrenos irregulares.

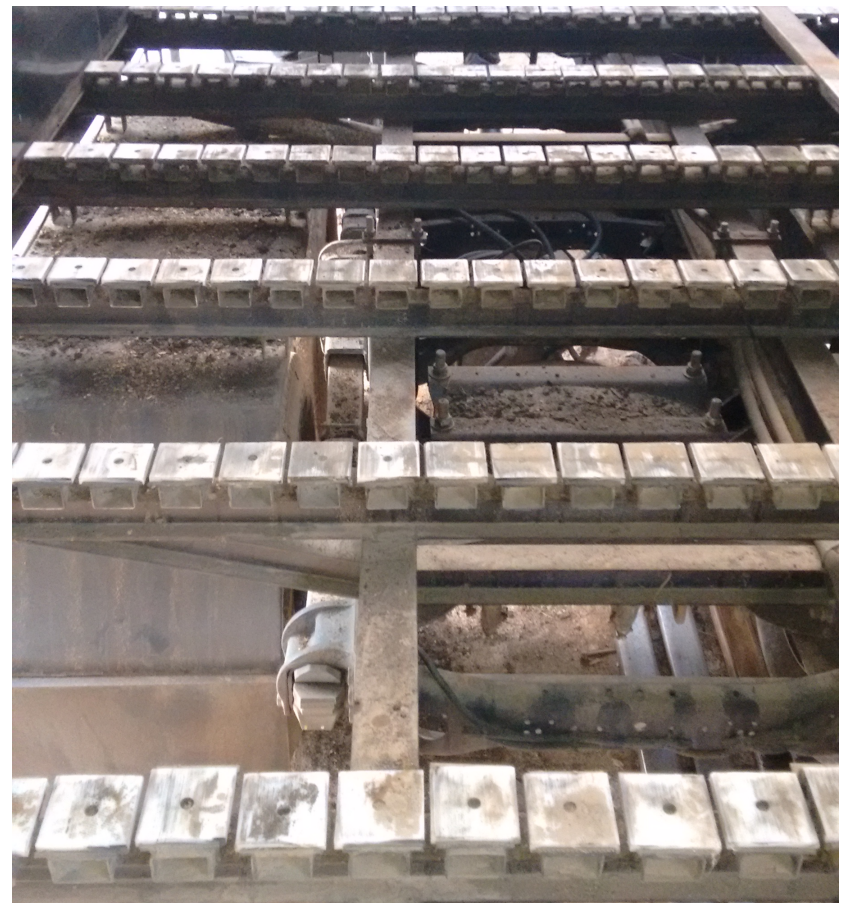

Figura 6. Suportes de tecnil (vista superior)

A parte móvel do piso é composta por 24 perfis, conectados a grupos de 8 perfis intercalados, presos a chapas ortogonais ao piso. Cada grupo corresponde a $1 / 3$ da área total do piso. Conforme apresentada na Figura 9, essas chapas foram fixadas individualmente a três pistões hidráulicos, responsáveis pela movimentação do conjunto. O controle da movimentação foi desenvolvido utilizando-se um comando hidráulico acionado eletricamente que direciona o fluxo de óleo individualmente para os cilindros. Ao ser energizado, o comando direciona a pressão para um lado do cilindro, movendo seu êmbolo. Ao desenergizar, a pressão é direcionada para o outro lado invertendo o 


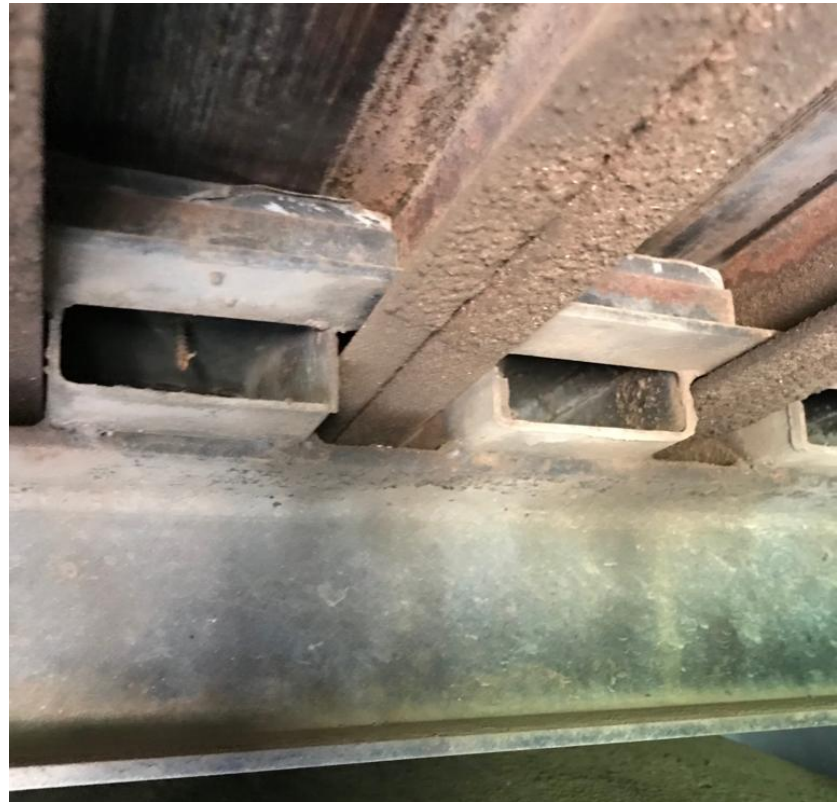

Figura 7. Suportes de tecnil (vista inferior)

sentido do movimento. A sincronização do movimento é obtida por meio de chaves elétricas conectadas ao final de curso de cada pistão, seguindo a logica mostrada na Figura 8. O ciclo de carregamento ou de descarregamento é escolhido pelo operador em um painel de controle. A tração é desenvolvida por uma bomba hidráulica acionada na caixa de cambio do caminhão utilizando uma tomada de força.

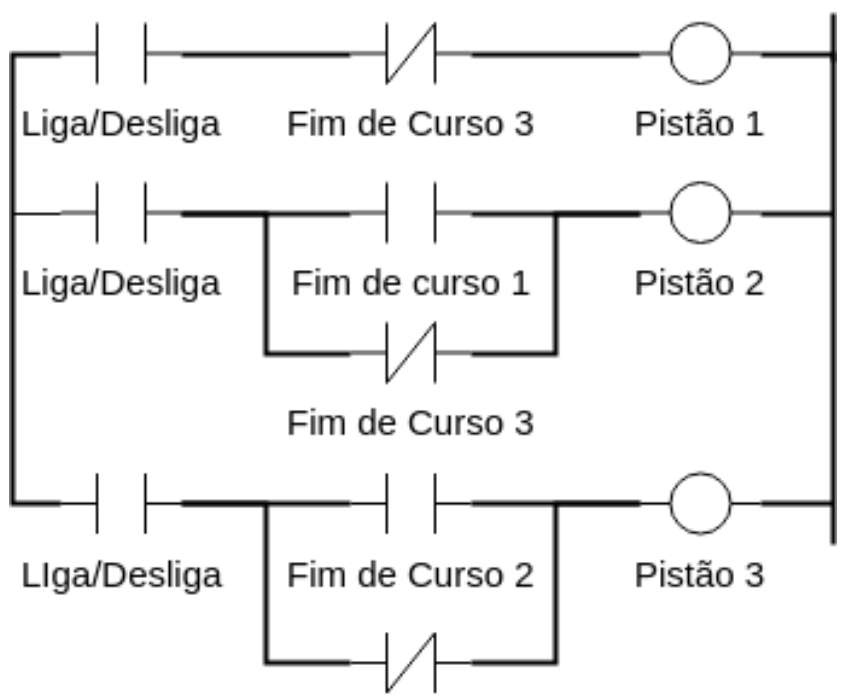

\section{Fim de Curso 3}

Figura 8. Diagrama de acionamento

A caixa de carga, ilustrada na Figura 10, foi construída utilizando-se chapas de aço de $2 \mathrm{~mm}$ de espessura e os perfis verticais de 50 x $50 \mathrm{~mm}$ e $3 \mathrm{~mm}$ de espessura. Possui a capacidade nominal de $75 \mathrm{~m}^{3}$ e com estrutura independente do piso, sobre o qual é fixada por parafusos. Isso possibilita sua remoção para o uso do caminhão no transporte de cargas que necessitem de uma carroceria no modelo convencional.

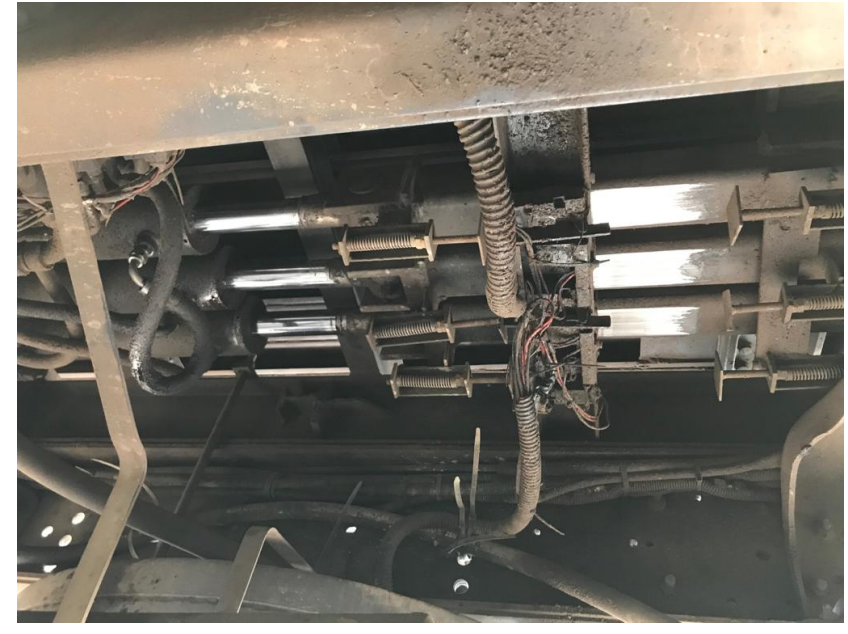

Figura 9. Mecanismo hidráulico responsável pela movimentação do piso

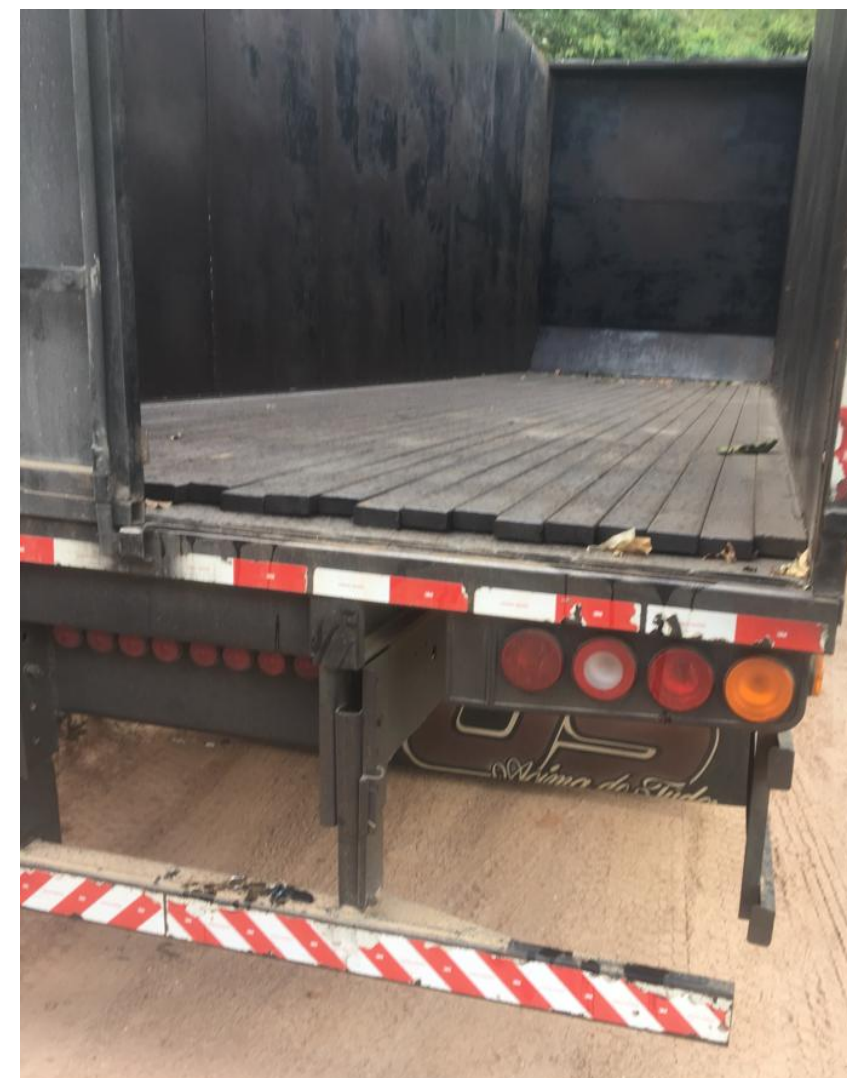

Figura 10. Caixa de carga

Em complemento, desenvolveu-se um sistema de sucção para o carregamento de palha de café, conforme ilustrado na Figura 12, tendo por base um exaustor, cujo motor possui $25 \mathrm{cv}$ de potência nominal, e que conduz uma mistura, de palha e ar, do chão para o interior da caixa de carga. O sistema foi instalado na parte traseira da caixa de carga e acoplado a uma porta elevatória. Esta porta é aberta por um conjunto de dois pistões impulsionados pelo sistema hidráulico de potência, possibilitando, assim, a abertura completa para o descarregamento, como na Figura 13. 


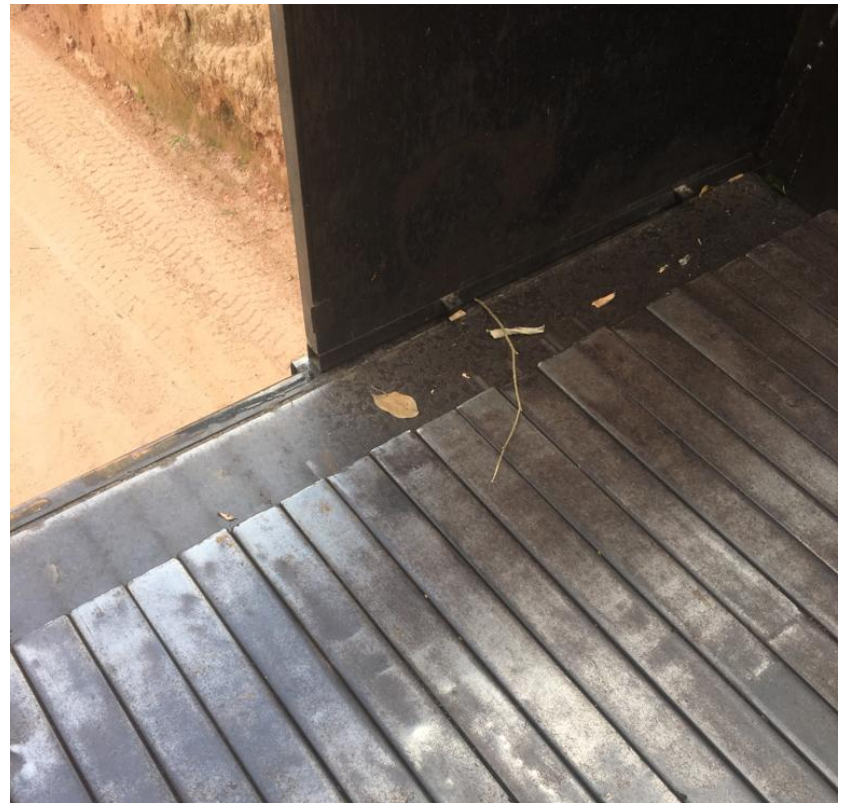

Figura 11. Piso

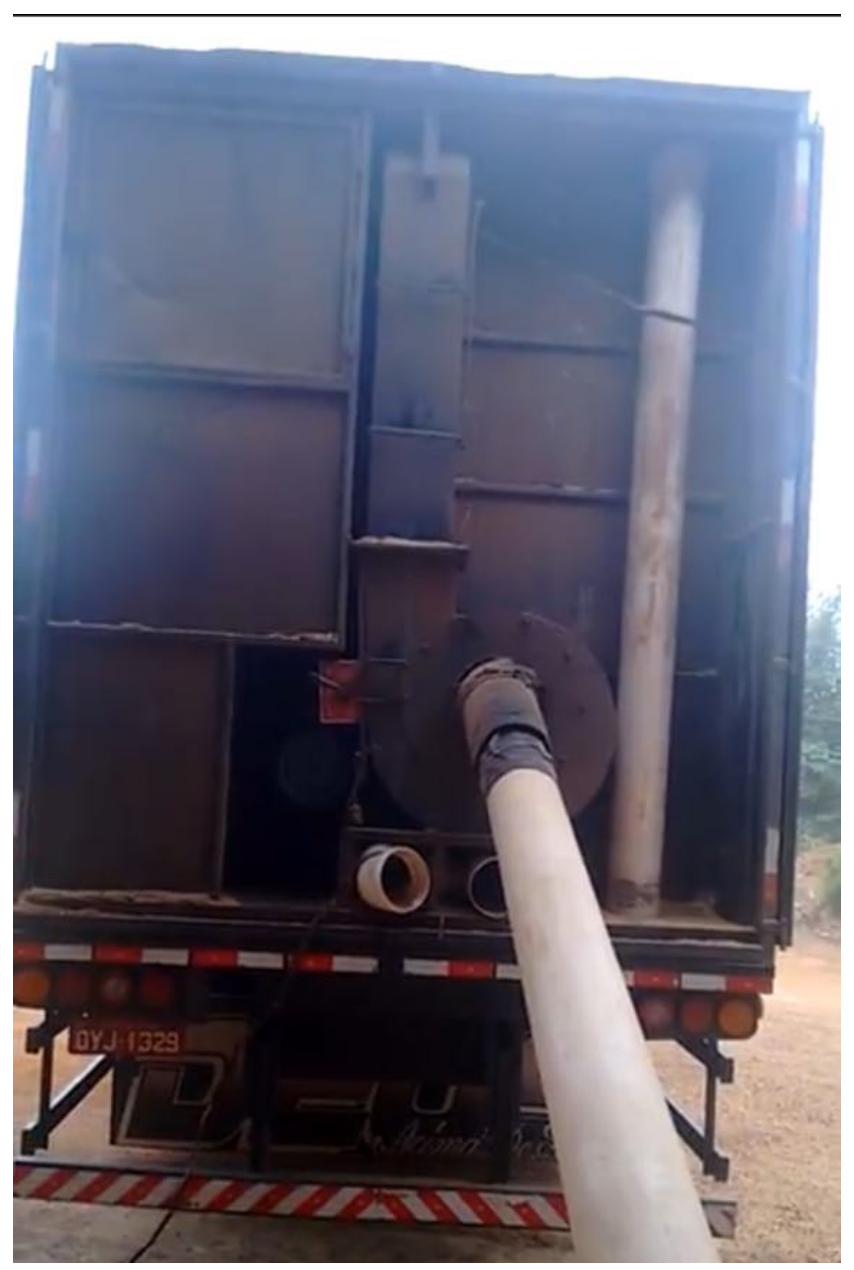

Figura 12. Sistema de sucção

\section{RESULTADOS E DISCUSSÕES}

O sistema desenvolvido está em operação há 5 anos sem apresentar problemas. Nesse período, foram realizados os

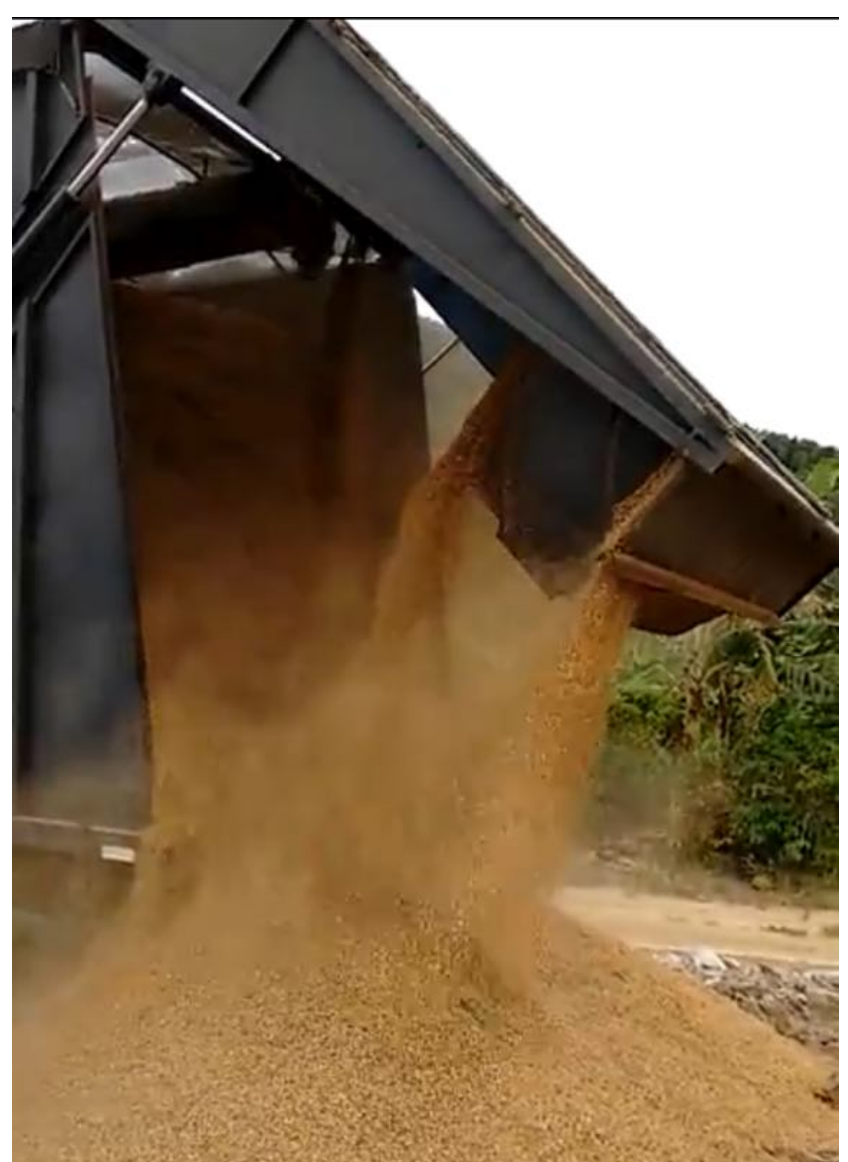

Figura 13. Porta elevadiça

transportes de diferentes tipos de carga, a citar: cavaco de madeira, silagem de milho, serragem, cimento em palets e palha de café. O sistema foi eficaz em todas as variedades de carga citadas, sendo, predominantemente, utilizado no transporte de palha de café e cavaco de madeira.

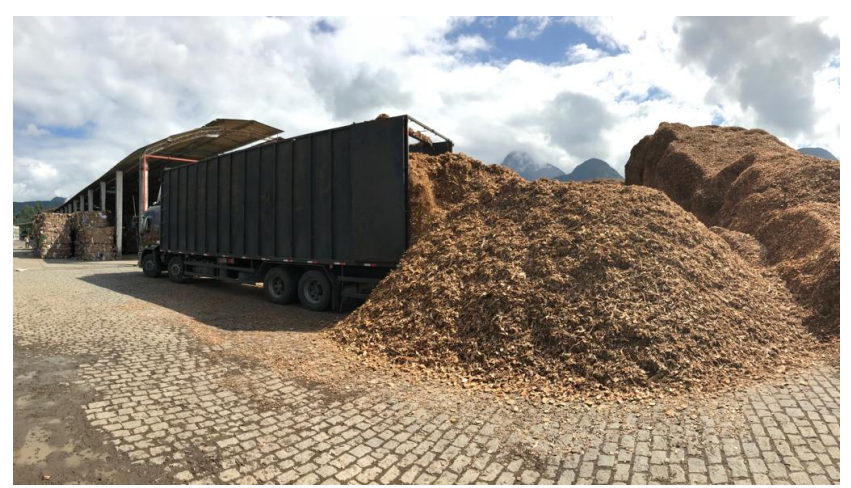

Figura 14. Descarregamento de cavaco de madeira

O tempo médio de descarregamento variou entre 10 e 15 minutos, e depende da granulosidade e da densidade da carga. Foram realizados testes de descarregamento de até 33 toneladas de material, pois com esse valor, o peso bruto total extrapolava os limites de peso permitido para a circulação rodoviária desta categoria de veículo.

Durante dois anos o implemento foi aplicado no transporte de palha de café utilizada em caldeiras e como fertilizante orgânico. A palha era oriunda das centrais de beneficiamento instaladas nas propriedades rurais. O desenvolvi- 
mento do sistema de carregamento por sucção foi decorrente da necessidade automatização deste processo, dado que tais locais não dispunham de mão de obra ou máquinas carregadeiras. O carregamento automatizado dura de três e quatro horas, produzindo muita poeira. Com isso, optouse por utilizar um motor elétrico para o exaustor, pois o haveria excesso de particulado no filtro de admissão do caminhão. Além disto, todos os pontos de carregamento dispunham de acesso à rede elétrica.

Comparação o sistema desenvolvido (desconsiderando o sistema para carregamento de palha de café) com um sistema utilizando o piso móvel da marca Hyva (em mesma categoria de caminhões) é possível identificar significativa redução no custo, em conjunto com redução do peso. $\mathrm{O}$ implemento desenvolvido apresentou $75 \mathrm{~m}^{3}$ de volume interno, com massa de, aproximadamente, $5600 \mathrm{~kg}$. O sistema com piso móvel Hyva, possui $68 \mathrm{~m}^{3}$, com, aproximadamente, $7100 \mathrm{~kg}$. Em vista do fato que, na maioria dos casos, a carga é vendida pelo volume e o excesso de peso é um problema corriqueiro nas estradas brasileiras, destaca-se a redução de aproximadamente $1500 \mathrm{~kg}$ da massa total em um sistema com capacidade de $7 \mathrm{~m}^{3}$ superior. Na Figura 14, exemplifica-se o final de um processo de descarga de biomassa (cavaco de madeira). No decorrer dos 5 anos de uso diário, o implemento não apresentou nenhum tipo de anomalia estrutural, como rompimentos de soldas, empenamento da estrutura, ou desgastes mecânicos expressivos decorrentes do atrito entre as peças moveis. Os principais materiais utilizados na manufatura do piso móvel e do sistema de carregamento por sucção são listados na Tabela 1.

Tabela 1. Principais materiais utilizados.

\begin{tabular}{ccc} 
Peça & Especificação & Quantidade \\
\hline Perfil I & 6 polegadas & 3 \\
Perfil I & 3 polegadas & 10 \\
Perfil U & $2 \mathrm{~mm} \times 100 \mathrm{~mm}$ & 30 \\
Perfil fechado & $50 \times 50 \times 3 \mathrm{~mm}$ & 25 \\
Chapa de aço & $2 \mathrm{~mm}$ & 22 \\
Bomba hidráulica & $0,15 \mathrm{~m}^{3} / \mathrm{min}$ & 1 \\
pistões hidráulicos & 4 polegadas & 3 \\
pistões hidráulicos & 3 polegadas & 2 \\
Comando hidráulico & Eletrônico & 1 \\
Reservatório de óleo & $0,1 \mathrm{~m}^{3}$ & 1 \\
Mangotes hidráulicos & $1 / 4$ polegada & 10 \\
Chave de fim de curso & Duas posições & 10 \\
Exaustor & Entrada de 25 polegadas & 1 \\
Motor elétrico & $25 \mathrm{cv}$ & 1 \\
Chapa de tecnil & $80 \times 80 \times 10 \mathrm{~mm}$ & 360 \\
\hline
\end{tabular}

\section{CONCLUSÃO}

O sistema de piso móvel desenvolvido, para transporte rodoviário de biomassa, apresentou uma redução média de $40 \%$ do custo e aumento em $7 \mathrm{~m}^{3}$ da capacidade de carga, em relação às soluções comerciais da mesma categoria. Mesmo optando pela construção do piso em aço, sua massa apresentou $1500 \mathrm{~kg}$ a menos do que o sistema em alumínio. Isso o torna competitivo, uma vez que o valor do frete é função da capacidade de carga e que o excesso de carga acarreta em multas. A utilização em conjunto ao sistema de carregamento por sucção, possibilitou a atuação em ambientes desprovidos de maquinários, viabilizando o escoamento de insumos das pequenas propriedades que dispunham de maquinários de beneficiamento de café e não tinham meios para descartar ou consumir a palha gerada.

O sistema de carregamento por exaustão aumentou a eficiência do processo, porém produzia muita poeira, o que causava desconforto quando o carregamento era efetuado próximo a áreas residenciais. Pontos do projeto ainda podem ser melhorados afim de reduzir o seu custo de produção, bem como sua massa. Por exemplo: a utilização de um comando hidráulico de acionamento mecânico, em substituição do elétrico, para a movimentação do piso; aumento da resistência mecânica da caixa de carga com o calandramento das chapas laterais e assim diminuir o número de perfis verticais; utilização de chapas e perfis galvanizados para aumentar a durabilidade.

\section{REFERÊNCIAS}

Bolsen, K.K. (2018). Silage review: Safety considerations during silage making and feeding. Journal of dairy science, 101(5), 4122-4131.

Drozdziel, P., Wawer, K., Madlenak, R., and Mussabekov, M.O. (2017). Concepts of load handling devices, adjusted to light goods vehicles of the weight up to $3.5 \mathrm{t}$. Communications-Scientific letters of the University of Zilina, 19(2), 96-102.

Fayed, M.E. and Skocir, T. (1996). Mechanical conveyors: selection and operation. CRC Press.

Foster, R.K. (1985). Drive/guide system for a reciprocating floor conveyor. US Patent 4,492,303.

Foster, R.K. (1989). Improved drive system for a reciprocating floor conveyor. US Patent 4,823,938.

Kwo, T. (1958). A theory of conveyors. Management science, $5(1), 51-71$.

Lewandowski, K. (2014). Reliability of the delivery in the last 100 meters. In Safety and Reliability: Methodology and Applications-Proceedings of the European Safety and Reliability Conference, ESREL.

McGuire, P.M. (2009). Conveyors: application, selection, and integration. CRC Press.

Miao, Z., Shastri, Y., Grift, T.E., Hansen, A.C., and Ting, K. (2012). Lignocellulosic biomass feedstock transportation alternatives, logistics, equipment configurations, and modeling. Biofuels, Bioproducts and Biorefining, 6(3), 351-362.

Mustafa, A., Calay, R.K., Mustafa, M., and Das, S. (2016). Smart production of biofuel for small communities. In 2016 International Symposium on Small-scale Intelligent Manufacturing Systems (SIMS), 7-12. IEEE.

Muth, E.J. and White, J.A. (1979). Conveyor theory: a survey. Aiie Transactions, 11(4), 270-277.

Skocir, T. (2018). Mechanical Conveyors: Selection and Operation. Routledge.

Wang, W.B., Cheng, K., and Cheng, L. (2014). Parametric modeling and analysis of self-loading container vehicle based on ansys. In Applied Mechanics and Materials, volume 620, 137-142. Trans Tech Publ.

Williams, E.J. and Çelik, H. (1998). Analysis of conveyor systems within automotive final assembly. In 1998 Winter Simulation Conference. Proceedings, volume 2, 915-920. IEEE. 